\title{
Geographical location and habitat predict variation in prokaryotic community composition of Suberites diversicolor
}

\author{
Marina Rafaela Santos Ferreira ${ }^{1 *} \mathbb{D}$, Daniel Francis Richard Cleary ${ }^{1}\left(\mathbb{D}\right.$, Francisco José Riso Costa Coelho ${ }^{1} \mathbb{D}$, \\ Newton Carlos Marcial Gomes ${ }^{1}$ [D, Yusheng M Huang ${ }^{2,3}$ (D) Ana Rita Moura Polónia ${ }^{1}$ (i) and Nicole Joy de Voogd ${ }^{4,5}$ (D)
}

\begin{abstract}
Purpose: Marine lakes are unique habitats that house diverse assemblages of benthic and planktonic organisms including endemic species. In this study, we aimed to assess to what extent geographical location (Berau versus Papua) and the degree of marine lake connectivity (relatively open versus closed) to the surrounding marine environment structures the prokaryotic community composition of the sponge species Suberites diversicolor.
\end{abstract}

Methods: Sponge specimens were sampled in five marine lakes in Borneo and Papua and one open sea habitat in Taiwan.

Result: Prokaryotic communities of $S$. diversicolor were dominated by members assigned to the Proteobacteria (particularly Alphaproteobacteria and Gammaproteobacteria) and Cyanobacteria, which together made up from 78 to $87 \%$ of sequences in all samples. The dominant operational taxonomic units (OTUs) in most samples, OTUs 1 and 3, were both assigned to the alphaproteobacterial order Rhodospirillales with OTU-1 dominant in the marine lakes of Berau and Papua and OTU-3 in Taiwan. OTU-3 was also largely absent from Papuan samples but present in all Berau samples. Compositionally, S. diversicolor samples clustered according to geographical location with the main axis of variation separating marine lake samples collected in Berau from those collected in Papua and the second axis of variation separating open sea samples collected in Taiwan from all marine lake samples. In addition, our results suggest that the degree of lake connectivity to the open sea also influences prokaryotic composition.

Conclusion: Although previous studies have shown that sponge-associated microbial communities tend to be stable across different geographical and environmental gradients, in the present study, both geography and local environmental conditions were significant predictors of variation in prokaryotic community composition of $S$. diversicolor.

Keywords: Anchialine systems, Composition, Illumina, Porifera, Indonesia, Taiwan

\section{Introduction}

Marine lakes, also known as anchialine systems, are small seawater bodies, isolated in the interior of islands and connected to the surrounding marine environment through subterranean fissures, tunnels or small dissolution channels in the surrounding rock (Holthuis 1973; Hamner and Hamner 1998; Becking et al. 2011, 2013a). Based on the connection to the sea, marine lakes can be limnologically classified as holomictic or meromictic.

\footnotetext{
* Correspondence: mrsf@ua.pt

${ }^{1}$ Department of Biology \& CESAM, University of Aveiro, Aveiro, Portugal Full list of author information is available at the end of the article
}

Holomictic lakes are well connected to the outer marine environment, and at least once each year, there is a physical mixing of superficial and deeper waters. In contrast, meromictic lakes have limited connection to the surrounding marine environment. Consequently, waters tend to stratify in meromictic lakes with denser water (saline) in the deeper parts and less dense fresher water closer to the surface (Gotoh et al. 2011; Saitoh et al. 2011). The connection between the marine lakes and the outer marine environment strongly influences the communities inhabiting these lakes (Saitoh et al. 2011). Lakes with a limited connection tend to house a smaller 
number of species including numerous endemics (Becking et al. 2013a, 2013b, 2016; Strelkov et al. 2014), whereas more connected lakes tend to house more species, but with a greater compositional similarity to open sea habitat. Lake size also influences the number of species, with larger lakes housing a higher number of species than smaller ones (Becking et al. 2013b). In addition to differences in species number, connectivity also influences the lake environment with less connected lakes usually characterised by lower $\mathrm{pH}$, lower salinity and higher water temperature than more connected lakes (Becking et al. 2011). These differences in environmental conditions make comparisons among lakes with different degrees of connection to the open sea particularly interesting. Marine lakes may provide some information on the long-term impact of low $\mathrm{pH}$ conditions on symbiont composition, although care must be taken in interpreting results due to the confounding effect of lower salinity, which can also have a profound effect on prokaryotic composition (Meyerhof et al. 2016).

Previous studies have focused on the abundance and diversity of various organisms including algae, ascidians, molluscs and sponges inhabiting marine lakes in Indonesia, Palau and Vietnam (Hoeksema 2004; Cerrano et al. 2006; Becking et al. 2011). Sponges (phylum Porifera) are the most basal of Metazoans (Borchiellini et al. 2001) and have been considered living fossils (Müller 1998; Oláh et al. 2017). They inhabit a range of habitats from tropical to polar seas, shallow to deep waters and marine, brackish and freshwater environments (Ruetzler 2004). Sponges have been shown to house numerous microorganisms including Bacteria, Archaea, fungi and dinoflagellates (Lee et al. 2011; He et al. 2014; Cleary 2019). These microorganisms can make up to $35 \%$ of sponge biomass and have been shown to play key roles in the sponge metabolism, including carbon and nitrogen cycling and chemical defence (Webster et al. 2010; Bolaños et al. 2015). The role of symbiotic microorganisms in bioactive metabolite production has further fostered interest in these organisms (Park et al. 2019). The interactions between sponges and their symbiotic microorganisms have been studied and characterised (Bolaños et al. 2015), but the majority of symbiotic bacteria found in sponges have not yet been cultivated (Cleary et al. 2013; He et al. 2014). In order to overcome this problem, nucleic acid-based molecular techniques have emerged. These techniques provide much more detailed information with respect to the diversity and composition of the sponge microorganisms (Cleary et al. 2013; He et al. 2014).

The diversity and abundance of sponge-associated prokaryotes have been previously studied for different sponge species (Cleary et al. 2013, 2015; de Voogd et al. 2015; Polónia et al. 2015). These studies have revealed pronounced variation in prokaryotic composition among different sponge species, and between sponges and the surrounding environment including water and sediment. There is, however, some debate on the degree to which prokaryotic communities vary within the same sponge species and the role of environmental conditions and geographical isolation herein (Burgsdorf et al. 2014; Luter et al. 2015; Moitinho-Silva et al. 2017). Lee et al. (2011), for example, found that there was relatively little variation in the composition of bacteria in the sponge species Hyrtios erectus, Stylissa carteri and Xestospongia testudinaria despite pronounced differences in the environments from which the specimens were collected. In contrast, Luter et al. (2015) found marked differences in the bacterial composition of specimens of the sponge Carteriospongia foliascens collected in the inshore Fantome and Orpheus Islands, and in Great Barrier Reef communities at Green Island and Davies Reef (Luter et al. 2015). Likewise, Swierts et al. (2018) found geography to be a significant determinant of prokaryotic community composition in Indo-Pacific barrel sponges (Xestospongia spp.). In order to fulfil this lack of knowledge and understand how geographical location and marine lake connectivity influence prokaryotic community composition, we assessed the prokaryotic communities of the sponge S. diversicolor Becking and Lim 2009 (Demospongiae: Hadromerida: Suberitidae) across three distinct geographical locations (Borneo, Papua and Taiwan) and two distinct marine lake habitats (relatively open and closed marine lake environments). The distribution of $S$. diversicolor makes it an ideal model to study intraspecific variation in prokaryotic composition. This sponge species can be found inside and outside of marine lakes with different degrees of connection to the surrounding sea and is able to adapt to environments with unfavourable conditions, such as low salinity or periodic exposure to air (Becking et al. 2013b). The genus Suberites presently contains 78 species with a worldwide distribution. Only seven have been reported from the Indo-Pacific region. Suberites diversicolor is mainly known from marine lakes in Vietnam, Indonesia and possibly Palau but also occurs in coastal mangrove systems and a man-made pool in northern Australia (Becking and Lim 2009).

Previous studies of the prokaryotic composition of $S$. diversicolor have shown relatively minor compositional variation between samples from inside and outside lakes within the Berau Delta barrier reef system (Cleary et al. 2013). However, when comparing specimens from related species from different environments, such as coral reefs and hydrothermal vents, differences between bacterial communities were observed (Coelho et al. 2018). Cleary et al. (2013) and Coelho et al. (2018) identified Alphaproteobacteria as the dominant taxa 
within S. diversicolor with the dominant OTUs assigned to the Kiloniellales order (Cleary et al. 2013; Coelho et al. 2018).

The aims of the present study were to (i) compare richness and composition of sponge-associated microbial communities of $S$. diversicolor specimens collected from different environments (marine lakes with different degrees of connectivity to the open sea and open sea habitat) and geographical locations (Borneo, Papua, Taiwan), (ii) identify the most abundant OTUs and closely related sponge-associated microorganisms using BLAST search, and (iii) evaluate if geographical location and the degree of connectivity of marine lakes to the surrounding open sea are significant predictors of the variation in the structural composition of sponge prokaryotic communities.

\section{Material and methods Location}

Samples of S. diversicolor (Demospongiae: Hadromerida: Suberitidae) were collected by snorkelling inside the marine lakes of Berau, East Kalimantan Province, Borneo, Indonesia, and in the Southeast Misool region, West Papua Province, Indonesia, and by SCUBA diving in open sea habitat in the Penghu archipelago, Taiwan (Supplementary File 1; Supplementary File 2).

The coastal system of Berau consists of different ecosystems including coral reefs and mangroves. The marine lakes in the present study were located on the islands of Kakaban and Maratua. Three marine lakes were sampled in Berau, namely, lake Kakaban, lake Haji Buang and lake Tanah Bamban. Previous studies have provided detailed descriptions of these lakes (Tomascik and Mah 1994; Tomascik et al. 1997; Becking et al. 2011; Cleary et al. 2018a). In brief, Kakaban lake (BrK, $\mathrm{N}_{2}^{\circ} 08^{\prime} 23.5^{\prime \prime} \mathrm{E} 118^{\circ} 30^{\prime} 31.9^{\prime \prime}$ ) is located within Kakaban island and is surrounded by mangroves. Kakaban lake, the largest (ca. $4 \mathrm{~km}^{2}$ ) lake sampled in this study, had a tidal amplitude dampened to $11 \%$ of the surrounding sea and a 3.5-h tidal phase delay. Salinity in lake Kakaban varied from 23 to 24 ppt and temperature from 29 to $31.5{ }^{\circ} \mathrm{C}$. This is an indication that the connection with the surrounding environment is limited (Tomascik and Mah 1994; Becking et al. 2011; Cleary et al. 2018a). Kakaban lake also differs from the marine lakes of Maratua in being a former atoll lagoon and not a karstic marine lake (Tomascik T, pers. comm.). Haji Buang lake (BrM, N02 $\left.{ }^{\circ} 12^{\prime} 31.2^{\prime \prime} \mathrm{E} 118^{\circ} 35^{\prime} 46.7^{\prime \prime}\right)$ and Tanah Bamban lake (BrT, N02 ${ }^{\circ} 13^{\prime} 50.0^{\prime \prime}$ E118 34' 50.7") are located in Maratua Island. Both of these lakes are considerably smaller (Haji Buang Lake is ca. 0.14 $\mathrm{km}^{2}$ and Tanah Bamban lake is ca. $0.12 \mathrm{~km}^{2}$ ) and more connected to the surrounding sea than lake Kakaban. The tidal amplitude of Haji Buang was dampened to
$48 \%$ of the surrounding sea with a tidal delay of $2.5 \mathrm{~h}$ (Becking et al. 2016). Salinity and temperature in Haji Buang ranged from 26 to $28.5 \mathrm{ppt}$ and from 29 to $30{ }^{\circ} \mathrm{C}$, respectively. Salinity and temperature in Tanah Bamban ranged from 26 to $28.5 \mathrm{ppt}$ and 29 to $30^{\circ} \mathrm{C}$, respectively. The reported presence of a resident saltwater crocodile did not allow a more in-depth study of the lake environment of Tanah Bamban; however, Tanah Bamban had the greatest connectivity to the open sea as indicated by the relatively high salinity (Cleary et al. 2016). The marine lakes of West Papua are located in two different islands in Southeast Misool, Raja Ampat region, West Papua Province, Indonesia. Southeast Misool includes 343,200 ha of a marine protected area established in 2009 (KKPD Misool Timur-Selatan). The waters surrounding both islands are highly diverse (Becking et al. 2015). The lakes do not yet have formal names and are here identified as marine lake $\mathrm{K}(\mathrm{PaK})$ and marine lake $\mathrm{M}$ (PaM). Marine lake K (S02 ${ }^{\circ} 13^{\prime} 13.77^{\prime \prime} \mathrm{E} 130^{\circ} 27^{\prime}$ $\left.32.03^{\prime \prime}\right)$ is located in Karawop island and is 72 by $64 \mathrm{~m}$ at its widest point. Marine lake $\mathrm{K}$ had a tidal amplitude of $45 \mathrm{~cm}$ and a 3-h tidal delay indicating a limited connection to the sea (Cleary et al. 2018b). Salinity and temperature recorded in marine lake $\mathrm{K}$ were $28.9 \mathrm{ppt}$ and $31.5{ }^{\circ} \mathrm{C}$, respectively. Marine lake $\mathrm{M}$ ( $\mathrm{S} 01^{\circ}{ }^{5} 9^{\prime}$ $\left.02.29^{\prime \prime} \mathrm{E} 130^{\circ} 30^{\prime} 58.95^{\prime \prime}\right)$ is located within a small island to the east of Misool Island. There was relatively little difference between the lake and the sea in terms of tidal amplitude and tidal lag indicating pronounced connection with the surrounding sea. Salinity and temperature recorded in marine lake $\mathrm{M}$ were $25.9 \mathrm{ppt}$ and $31.7{ }^{\circ} \mathrm{C}$, respectively. The relatively low salinity indicates that there is an important source of freshwater to the lake. These lakes were previously described by Becking et al. (2011), Klei (2016) and Cleary et al. (2018b).

Suberites diversicolor specimens from open sea habitat were collected in the Penghu archipelago, off the western coast of Taiwan (Fig. 1 in Huang et al. 2016). The coastal areas of the islands and islets are dominated by characteristic fringing reefs, with high abundance and biodiversity of subtidal sponges (Huang et al. 2016; Coelho et al. 2018). The waters surrounding this archipelago are influenced by three distinct currents, the cold southbound Chinese Coastal Current, the warm northbound South China Sea Current and the Kuroshio Current. A detailed description of this area can be found in Coelho et al. (2018) and Huang et al. (2016).

\section{Sampling}

Specimens of $S$. diversicolor were collected in Berau from the 21st to 30th August 2012, in Papua from the 15th to 16th September 2013 and in Taiwan from the 25th to 27th July 2014. 
Three replicates were sampled in both Papuan lakes and in Kakaban and Tanah Bamban; two replicates were sampled in Haji Buang marine lake and open sea habitat in Taiwan. All specimens were collected from relatively shallow water $(<5 \mathrm{~m}$ depth). In order to assess, as much as possible, the whole prokaryotic community, cores of each specimen were taken including segments of the surface and the interior of the sponge; these were stored in 95\% $\mathrm{EtOH}$ for microbial analysis. Sponge specimens were preserved in $70 \% \mathrm{EtOH}$ for later identification by Nicole de Voogd at Naturalis Biodiversity Center (Leiden, Netherlands). In addition to sponge samples, we also collected water samples between the depths of 1-2 m with a $1.5-\mathrm{L}$ bottle and subsequently $1 \mathrm{~L}$ of water was filtered through a Millipore ${ }^{\bullet}$ White Isopore Membrane Filter $(0.22 \mu \mathrm{m}$ pore size $)$ to obtain water prokaryotic communities.

\section{DNA extraction and next-generation sequencing analysis} We isolated PCR-ready genomic DNA from S. diversicolor samples using the FastDNA ${ }^{\circ}$ SPIN Kit (MPbiomedicals) following the manufacturer's instructions. This is an extraction method frequently used for this purpose (Costa et al. 2013; Urakawa et al. 2010). Briefly, the whole membrane filter (for water samples) and $500 \mathrm{mg}$ of sponge specimens were cut into small pieces and transferred to Lysing Matrix E tubes containing a mixture of ceramic and silica particles. The microbial cell lysis was performed in the FastPrep ${ }^{\circ}$ Instrument $(\mathrm{Q}$ Biogene) for $80 \mathrm{~s}$ at a speed of 6.0. The extracted DNA was eluted into DNase/Pyrogen-Free Water to a final volume of $50 \mu \mathrm{L}$ and stored at $-20{ }^{\circ} \mathrm{C}$ until use. The $16 \mathrm{~S}$ rRNA gene V3V4 variable region PCR primers $341 \mathrm{~F}$ 5'-CCTACGGGNGGCWGCAG-3' and 785R 5'-GACT ACHVGGGTATCTAATCC-3' (Klindworth et al. 2013) with barcode on the forward primer were used in a 30cycle PCR assay using the HotStarTaq Plus Master Mix Kit (Qiagen, USA) under the following conditions: $94{ }^{\circ} \mathrm{C}$ for $3 \mathrm{~min}$, followed by 28 cycles of $94{ }^{\circ} \mathrm{C}$ for $30 \mathrm{~s}, 53{ }^{\circ} \mathrm{C}$ for $40 \mathrm{~s}$ and $72{ }^{\circ} \mathrm{C}$ for $1 \mathrm{~min}$, after which a final elongation step at $72{ }^{\circ} \mathrm{C}$ for 5 min was performed. After amplification, PCR products were checked in $2 \%$ agarose gel to determine the success of amplification and the relative intensity of bands. Multiple samples were pooled together in equal proportions based on their molecular weight and DNA concentrations. Pooled samples were purified using calibrated Ampure XP beads. Pooled and purified PCR product was used to prepare the DNA library following the Illumina TruSeq DNA library preparation protocol. Next-generation, paired-end sequencing was performed at MRDNA (Molecular Research LP; http://www.mrdnalab.com/; last checked on 18 November 2016) on an Illumina MiSeq device (Illumina Inc., San Diego, CA, USA) following the manufacturer's guidelines. Sequences from each end were joined following Q25 quality trimming of the ends followed by reorienting any $3^{\prime}-5^{\prime}$ reads back into $5{ }^{\prime}-3$ ' and removal of short reads $(<150 \mathrm{bp})$. The resultant files were analysed using the QIIME software package (Quantitative Insights into Microbial Ecology; Caporaso et al. 2010; http://www.qiime.org/).

\section{S rRNA gene sequencing analysis}

For a detailed description of the sequence analysis, see Coelho et al. (2018) and Cleary et al. (2018a). Briefly, we used QIIME (Caporaso et al. 2010) and USEARCH (https://www.drive5.com/usearch/) for quality filtering and OTU clustering ( $97 \%$ sequence similarity threshold). Taxonomy was assigned to reference sequences of OTUs using default arguments in the assign_taxonomy.py script with the rdp method (Wang et al. 2007). In the assign_taxonomy.py function, we used a FASTA file containing reference sequences from the SILVA_128_ QIIME_release and the UCLUST classifier method in QIIME (Quast et al. 2012). For the OTU table, OTUs not classified as Bacteria or Archaea or classified as chloroplasts or mitochondria were removed prior to statistical analysis. Finally, we used the make_otu_ table.py script to generate a square matrix of OTUs $x$ SAMPLES and subsequently rarefied to 10,500 sequences per sample with the single_rarefaction.py script yielding 168,000 sequences assigned to 4522 OTUs. The DNA sequences generated in this study can be downloaded from the NCBI SRA: PRJNA479655.

\section{Statistical analysis}

The rarefied table containing OTU counts per sample was imported into R (R Core Team 2013) and used to compare community composition, estimate richness and assess the relative abundance of selected higher taxa. The OTU table was first $\log _{e}(x+1)$ transformed and a distance matrix constructed using the Bray-Curtis index. Variation in prokaryotic composition of $S$. diversicolor samples from different habitats was assessed with principal coordinates analysis (PCO) using the Bray-Curtis distance matrix as input. Compositional difference among habitats was tested for significance by adonis analysis in the vegan package in $\mathrm{R}$ (https://cran.r-project. org/web/packages/vegan/vegan.pdf) using the Bray-Curtis distance matrix as response variable and habitat as independent variable. The number of permutations was set at 999. We performed an additional analysis only including marine lake samples to test for differences in location (Berau versus Papua) and lake connectivity (open versus closed). Weighted average scores were computed for OTUs on the first four PCO axes. SIMPER analysis in vegan was used to identify significantly discriminating OTUs between pairs of habitats. The 
discriminating OTUs contribute the most to differences between pairs of habitats.

Following Cleary et al. (2018a), we tested for significant differences in the relative abundance of selected phyla, classes and orders among habitats from different geographical locations with an analysis of deviance in $\mathrm{R}$ using the $\operatorname{glm}()$ function. Post hoc analysis of estimated marginal means was performed using the emmeans function with the false discovery rate (fdr) method. A heatmap was constructed to visualise the distribution of the dominant OTUs ( $\geq 400$ sequences). The OTUs were log-transformed and clustered according to their occurrence by UPGMA hierarchical clustering. For a detailed description of the statistical analysis, see Cleary et al. (2019).

\section{Results}

In the present study, 168,000 sequences (after rarefying to 10,500 sequences per sample) were assigned to
4522 OTUs after quality screening and OTU filtering. OTUs were assigned to 57 phyla, 134 classes and 181 orders. Rarefied OTU richness was highest in samples from marine lakes and lowest in open sea habitat (Supplementary File 3).

The PCO analysis revealed compositional differences among locations and between relatively closed and more connected lakes (Fig. 1a). When only including the two most open and closed marine lakes from Berau and Papua (Fig. 1c), the factors' location (Berau versus Papua; adonis $\left.-F_{1,8}=3.34, R^{2}=0.207, P<0.001\right)$ and connection (BrK and PaK versus BrT and PaM; adonis$\left.F_{1,8}=2.50, R^{2}=0.154, P=0.003\right)$ were both highly significant predictors of variation in composition. There was also a highly significant interaction (adonis $-F_{1,8}=$ 2.33, $R^{2}=0.144, P=0.002$ ). The main axes of variation clustered samples according to the location (Fig. 1a). There were three different clusters: (1) samples from open sea habitat in Taiwan (Taw), (2) samples from
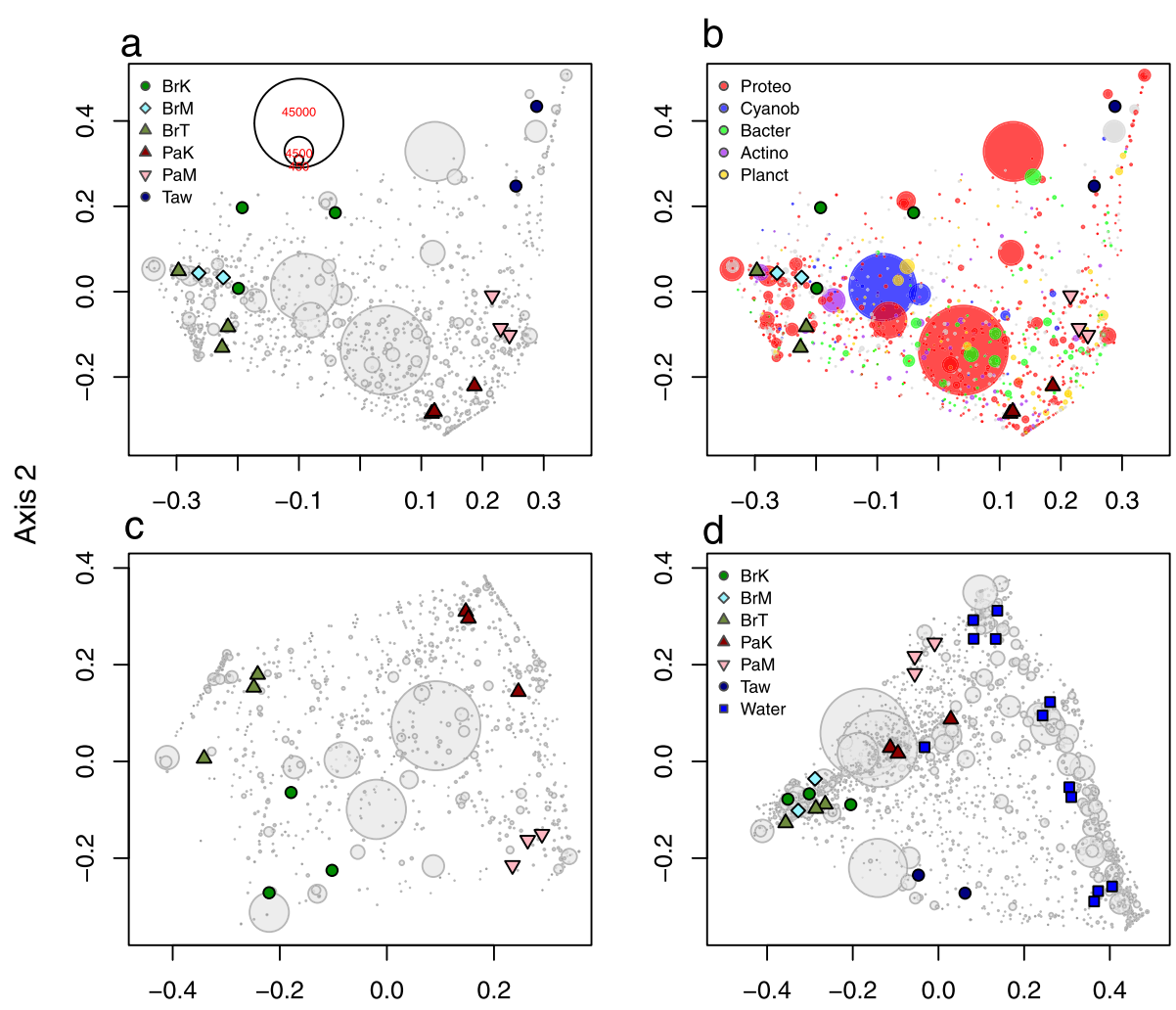

Axis 1

Fig. 1 Principal coordinates analysis (PCO) ordination of the first two axes. For each subfigure $(\mathbf{a}, \mathbf{b}, \mathbf{c}$ and $\mathbf{d})$, coloured symbols represent the sample site for S. diversicolor in marine lakes in Berau: Kakaban lake (BrK), Haji Buang lake (BrM), Tanah Bamban lake (BrT); Papua: Marine lake K (PaK), Marine lake M (PaM); and in open sea habitat: Taiwan (Taw). a OTU symbols are shown in grey and the circle size of the OTU is proportional to their abundance (number of sequences) as indicated by the symbol legend in the top left corner. b OTU symbols colour-coded according to their taxonomic assignment to selected phyla: Proteobacteria (red), Cyanobacteria (blue), Bacteroidetes (green), Actinobacteria (purple) and Planctomycetes (yellow). c PCO ordination including only the most open (BrT and PaM) and closed lakes (BrK and PaK) in Berau and Papua. d PCO ordination including S. diversicolor samples from Berau (BrK, BrM and BrT), Papua (PaM and PaK), open sea habitat in Taiwan (Taw), and water samples (water) 
marine lakes in Berau (BrK, BrM and BrT) and (3) samples from marine lakes in Papua (Pak and PaM). The first axis separated $S$. diversicolor samples from marine lakes in Berau from those sampled in the marine lakes in Papua and open sea habitat. The second axis separated samples from Taiwan from marine lake samples (Fig. 1a). The fourth axis of variation (Fig. 2) separated the samples according to the presumed level of connection to the marine environment, with $S$. diversicolor samples from marine lakes with lower connection (BrK and $\mathrm{PaK}$ ) at low axis 4 values and samples from more connected marine lakes ( $\mathrm{BrT}$ and $\mathrm{PaM}$ ) and open habitat at high axis 4 values. In addition to this, a PCO analysis including water samples from marine lakes and open habitat was performed. This analysis showed pronounced compositional differences between prokaryotic communities inhabiting $S$. diversicolor specimens and those inhabiting water (Fig. 1d). This was further confirmed by the adonis analysis ( $S$. diversicolor versus water; adonis $-F_{6,20}=3.075, R^{2}=0.480, P<0.001$ and $\left.F_{2,24}=4.303, R^{2}=0.264, P<0.001\right)$.

Overall, in $S$. diversicolor specimens, Proteobacteria was the most abundant phylum (108,947 sequences, 1801 OTUs), followed by Cyanobacteria (29,696 sequences, 89 OTUs), Bacteroidetes (8110 sequences, 448 OTUs), Actinobacteria (6335 sequences, 155 OTUs), Planctomycetes (4943 sequences, 426 OTUs) and Spirochaetes (2972 sequences, 37 OTUs) (Supplementary File 1). Proteobacteria and Cyanobacteria were the most abundant phyla in all locations (Fig. 3). After controlling for multiple comparisons, the only significant differences for phyla, however, were a significantly higher abundance of Cyanobacteria in marine lakes with lower connectivity to open sea (BrK, BrM and Pak) than in the Berau marine lake with greater connectivity $(\mathrm{BrT})$ and in the open sea habitat in Taiwan, together with a significantly higher abundance of Thaumarchaeota in Taiwan than all other habitats (Supplementary File 4). At a lower taxonomic level, there were also significant differences in the abundance of Deltaproteobacteria and the order Rhodobacterales among lakes. The abundance of Deltaproteobacteria was significantly higher in Haji Buang than all other habitats and significantly higher in lake $\mathrm{K}$ than lake $\mathrm{M}$ in Papua. The relative abundance of Rhodobacterales was significantly higher in lake Tanah Bamban than all habitats except Haji Buang (Supplementary File 4).

The most abundant OTUs observed were OTUs 1 (46, 749 sequences), 2 (26,240 sequences) and 3 (20,608 sequences) (Fig. 4). The heatmap in Fig. 4, only including the most abundant OTUs, also confirms the results of the PCO ordination with samples from open sea habitat in Taiwan and marine lake habitat in Berau and Papua forming distinct clusters. In total, there were 28 OTUs with $\geq 400$ sequences that significantly discriminated $(P<0.01)$ between pairs of habitats (Fig. 4 and Supplementary File 5). For example, OTU-1, assigned to the Rhodospirillales, and related to an organism obtained
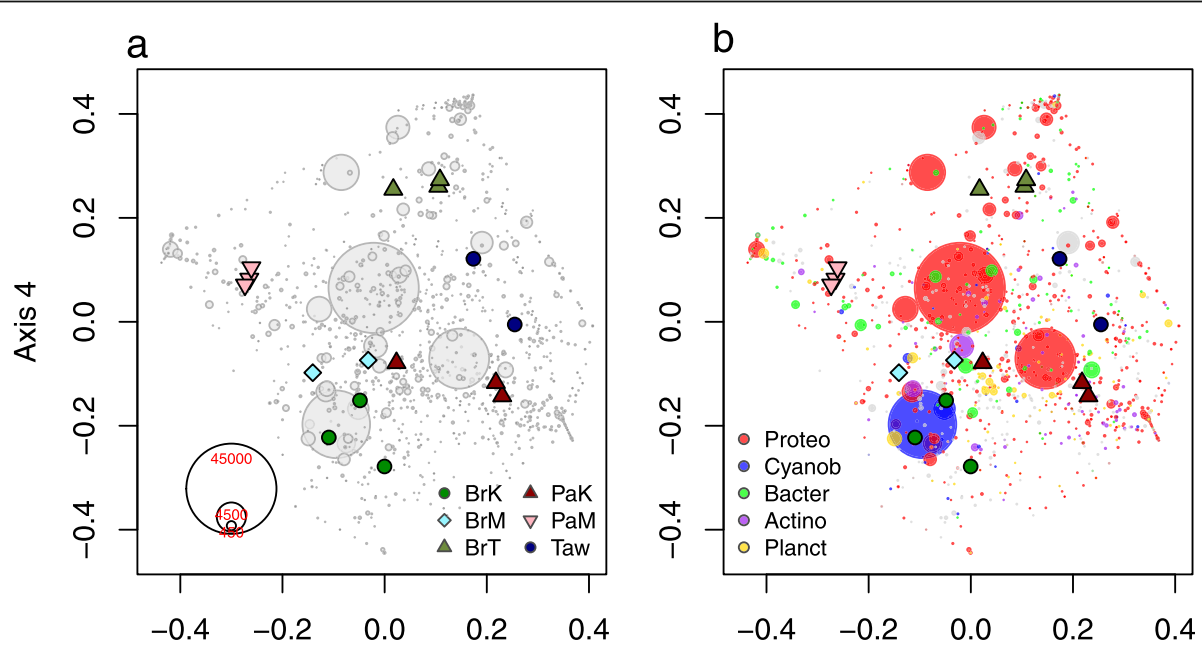

Axis 3

Fig. 2 Principal coordinates analysis (PCO) ordination of the third and fourth axes. For each subfigure (a and $\mathbf{b})$, coloured symbols represent the sample sites for S. diversicolor in marine lakes in Berau: Kakaban lake (BrK), Haji Buang lake (BrM), Tanah Bamban lake (BrT); Papua: Marine lake K (PaK), Marine lake M (PaM); and in open sea habitat: Taiwan (Taw). a OTU symbols are shown in grey and the circle size of the OTU is proportional to their abundance (number of sequences) as indicated by the symbol legend in the bottom left corner. b OTU symbols colourcoded according to their taxonomic assignment representing the five most abundant phyla: Proteobacteria (red), Cyanobacteria (blue), Bacteroidetes (green), Actinobacteria (purple) and Planctomycetes (yellow) 


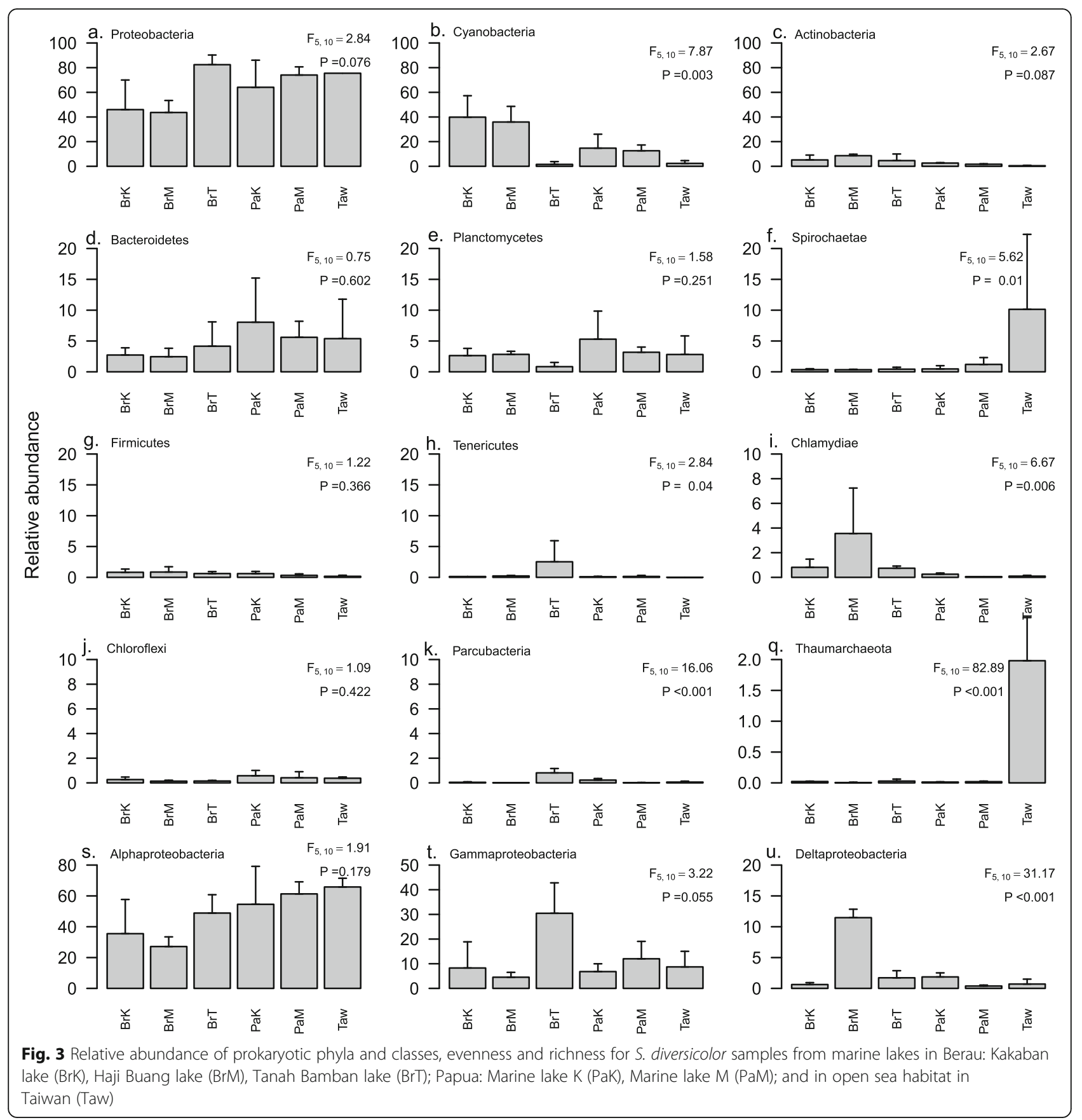

from marine reef sandy sediment, was most abundant in the smaller marine lakes from Berau and Papua and least abundant in Kakaban and open sea habitat and was closely related to an organism obtained from marine sediment. It significantly discriminated between open sea samples from Taiwan and all marine lakes with the exception of Kakaban (Supplementary Files 5 and 6). OTU-3, in contrast, also assigned to the Rhodospirillales, was most abundant in Kakaban and Taiwan and was also closely related to the same organism obtained from marine sediment to which OTU-1 was related. It significantly discriminated between Taiwan, Kakaban and the remaining marine lakes. OTU-167, assigned to the Thaumarchaeota, is closely related to an organism obtained from sediment and significantly discriminated between open sea habitat in Taiwan and all marine lakes (Supplementary File 6). Some OTUs were locally abundant in a single habitat (marine lake). For example, OTU-49, assigned to the Actinobacteria phylum, significantly discriminated between hosts from Haji Buang and hosts from all other habitats. OTUs 2 and 180, assigned to the Cyanobacteria, were least abundant in Tanah 


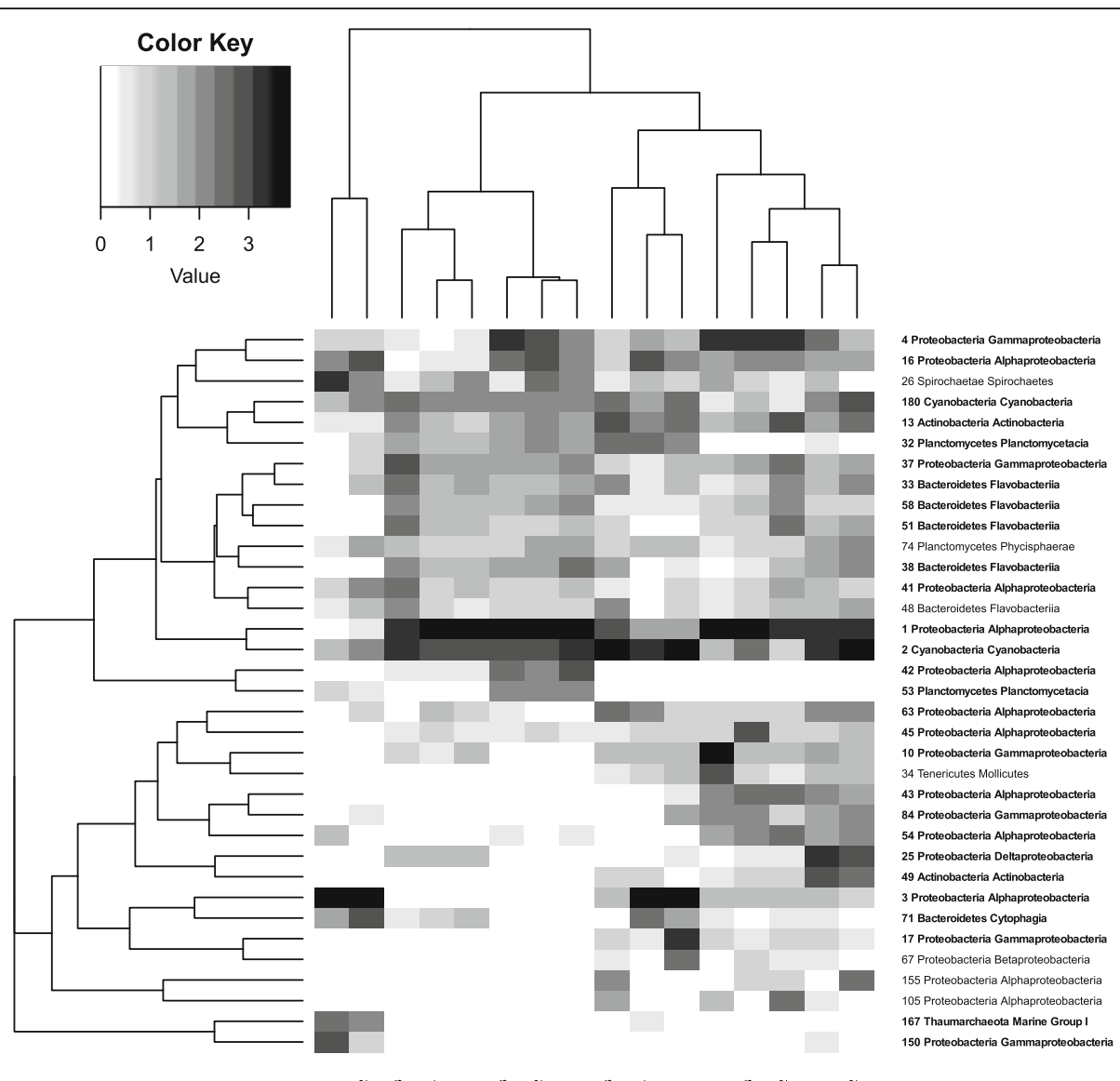

Fig. 4 Heatmap showing the abundance of dominant OTUs ( $\geq 400$ sequences reads). Abbreviations represent the sample sites for S. diversicolor in marine lakes in Berau: Kakaban lake (BrK), Haji Buang lake (BrM), Tanah Bamban lake (BrT); Papua: Marine lake K (PaK), Marine lake M (PaM); and in open sea habitat: Taiwan (Tw). Significantly discriminating OTUs $(P<0.01)$ identified using Simper are in bold

Bamban marine lake. OTU-180 significantly discriminated between hosts from the more connected Tanah Bamban marine lake and all other marine lakes. These OTUs are closely related to organisms obtained from seawater in Northern China (100\% and $99.77 \%$ similarity, respectively).

\section{Discussion}

Much research in sponge microbial ecology has focused on the prevalent role of sponge identity or biotope in structuring the microbial community, often neglecting the role of geographical variation (Webster et al. 2010; Lee et al. 2011). In the present study, we assessed the prokaryotic communities associated with the sponge $S$. diversicolor across a range of habitats from open sea to marine lake and across different geographical areas. OTUs assigned to Proteobacteria and Cyanobacteria were the most abundant members of the prokaryotic community of $S$. diversicolor. Less abundant phyla detected in this study included Actinobacteria, Bacteroidetes, Planctomycetes, Spirochaetae, Tenericutes,
Firmicutes and Chlamydiae, which have been previously observed in other sponge surveys (Hentschel et al. 2002; Giles et al. 2012; Schmitt et al. 2012; Cleary et al. 2013, 2015, 2018a; de Voogd et al. 2015).

At a lower taxonomic level, Alphaproteobacteria were, by far, the most abundant class, followed by Gamma-, Delta- and Betaproteobacteria. Members of these taxa have been observed in different sponge species from several different locations such as the Indian and Pacific Oceans, the Caribbean, Mediterranean and Red Sea (Schmitt et al. 2012), Berau Delta and barrier reef system in East Kalimantan, Indonesia (Cleary et al. 2013), Orpheus Island in Australia (Webster et al. 2013) and Korsfjord in Norway (Jensen et al. 2017). The dominance of Alphaproteobacteria was mainly due to members of the Rhodospirillales, and to a much lesser extent, members of the Rhodobacterales orders. Members of the Rhodospirillales (purple non-sulphur bacteria) and Rhodobacterales orders have been previously found in corals and in water (McDevitt-Irwin et al. 2017; Thiele et al. 2017). Previous studies have already associated 
Rhodospirillales and Rhodobacterales with sponges. Cleary et al. (2015) reported Rhodospirillales in sediment samples and samples of the sponge species Hyrtios erectus and Xestospongia testudinaria. Recently, Karimi et al. (2019) were able to obtain 46 isolates from the sponge species Spongia officinalis; 38 of these were assigned to the Rhodobacterales order. Other studies, however, reported Rhodobacterales as more abundant in seawater samples than in sponge samples (Polónia et al. 2016; Cleary et al. 2018c, 2018b). McDevitt-Irwin et al. (2017) reported an increased abundance of these taxa in response to different stressors (climate change, water pollution and overfishing) (McDevitt-Irwin et al. 2017). Thiele et al. (2017) observed members of these orders in water samples close to a polluted area (Thiele et al. 2017).

In the present study, the recently updated SILVA database (Balvočiūtè and Huson 2017) was used as opposed to the Greengenes database, which has not been updated since May 2013. The same sequence was assigned to Rhodospirillales by the SILVA database and to the Kiloniellales order using the Greengenes database. In this study, Rhodospirillales was the most abundant alphaproteobacterial order. Cleary et al. (2013) and Coelho et al. (2018) previously identified OTUs assigned to the Kiloniellales order as the most dominant members of the Alphaproteobacteria in S. diversicolor (Cleary et al. 2013; Coelho et al. 2018). This difference, is thus, due to the use of different taxonomic databases, namely SILVA versus Greengenes. This was also the case for lower cyanobacterial taxa. For example, the representative sequence of OTU-2 was assigned to the subsection I order using the SILVA database and the Synechococcales order using the Greengenes database.

Archaea made up a relatively minor component of the prokaryotic communities of $S$. diversicolor. There was, however, a significantly higher relative abundance of Thaumarchaeota in open sea samples from Taiwan than all other habitats. Previous studies have shown that members of Thaumarchaeota can be abundant in various sponge species (Turque et al. 2010; Polónia et al. 2015, 2016; Coelho et al. 2018). Polónia et al. (2015) previously showed that the abundances of mesophilic Crenarchaeota (recently adopted as Thaumarchaeota phylum) may be an indication of pollution levels (Polónia et al. 2015). The open sea samples of S. diversicolor in Taiwan were also sampled close to the densely inhabited main Penghu island of Magong, which is subject to a number of perturbations related to fishing, tourism and local industry. Alternatively, the environmental conditions inside marine lakes may not be advantageous to Thaumarchaeota members. Nitrosopumilus members have been shown to predominate in coastal environments when compared to freshwater or lake environments (Xie et al. 2014; Polónia and Cleary 2019) while the Cenarchaeum symbiosum species complex seems to have phylotypes specialised in both open water and marine lake environments (Polónia and Cleary 2019).

Much research in sponge microbial ecology has focused on the prevalent role of sponge identity in structuring the microbial community, often neglecting the role of geographical location (Webster et al. 2010; Lee et al. 2011). Overall, our results showed that S. diversicolor samples clustering primarily according to geographical location suggesting that spatial factors, or local environmental conditions, prevalent in each location, play a role in structuring the prokaryotic communities of this sponge species. This finding is in line with recent studies (Schmitt et al. 2012; Luter et al. 2015; Swierts et al. 2018). Luter et al. (2015) observed that the microbial community of Carteriospongia foliascens varied according to geographical location, while Swierts et al. (2018) showed that location was a more important explanatory factor in predicting variation in the prokaryotic communities of closely related Xestospongia species than genetic relatedness. Schmitt et al. (2012), when studying sponges from eight different locations, reported subtropical sponge microbial communities more similar to each other than to those found in tropical sponges. There was also a significant difference between sponge and water prokaryotic communities in the present study, which corroborates previous studies, which have shown that sponge-associated prokaryotic communities differ from those found in seawater (Hentschel et al. 2002; Taylor et al. 2005, 2007; Schmitt et al. 2012; Cleary et al. 2018a).

In addition to this, there was evidence for a role of lake connectivity to the open sea in structuring prokaryotic community composition, although playing a secondary role. The limited connection to the sea observed in lakes Kakaban and lake $\mathrm{K}$ in Papua allowed us to infer that they have characteristic behaviours of meromictic lakes. Indeed, both lakes are characterised by pronounced stratification of the water column due to, among other things, limited water turbulence (Becking et al. 2011; Gotoh et al. 2011; Saitoh et al. 2011). Differences in physical conditions can greatly influence phytoplankton communities (Reynolds 1980). The marine lakes of Berau were also shown to have distinct archaeal, bacterial and eukaryotic planktonic communities from those found in the surrounding open sea (Cleary and Gomes 2019). It has been shown that low water turbulence, as found in sheltered or meromictic lakes, can lead to the formation of dense cyanobacterial populations (Steinberg and Hartmann 1988). When turbulence is high, or mixing patterns are irregular, Cyanobacteria 
tend to be out-competed (Steinberg and Hartmann 1988). This data supports our findings, where S. diversicolor hosts from habitats with more pronounced connection to the open sea (Tanah Bamban and Taiwan) exhibited a lower abundance of OTUs assigned to Cyanobacteria, namely OTUs 2 and 180.

In addition to the above, $\mathrm{pH}$ also tends to be lower in lakes with a limited connection to the open sea (Becking et al. 2015). Cyanobacteria, particularly members of the genus Synechococcus, have been associated with low $\mathrm{pH}$ environments suggesting an environmental driver for the role of lake connectivity in structuring the prokaryotic communities of S. diversicolor (Cleary et al. 2013, 2018b, Morrow et al. 2016, Coelho et al. 2018, Cleary and Gomes 2019). The family Synechococcophycideae is, furthermore, known to be widely distributed in marine environments, whereby a subgroup was identified containing important symbionts of sponges (Schmitt et al. 2012; Burgsdorf et al. 2015). The Synechococcophycideae family consists of photosymbionts that play a significant role in biogeochemical cycles and have the ability to assimilate carbon and transfer it to the sponge (Freeman et al. 2013; Callieri 2017).

Despite pronounced differences in the relative abundance of several OTUs among habitats, these differences were much less pronounced at higher taxonomic levels with the exception of a few taxa including the Cyanobacteria and Thaumarchaeota. In other words, hosts from different locations had similar higher-level taxa, but location-specific OTUs. This OTU-level geographic specificity was previously suggested for the giant barrel sponge species complex Xestospongia spp. (Swierts et al. 2018). This suggests that $S$. diversicolor hosts provide a similar environment to their symbionts and that OTU composition may be driven by stochastic factors including spatial processes (Goldford et al. 2018).

OTUs 2 and 180 assigned to Cyanobacteria, at a lower taxonomic level related to the Synechococcales order, were present in all habitats, but significantly discriminated between the lake Tanah Bamban and other marine lakes. The most abundant OTU overall, OTU-1, was assigned to the Rhodospirillales order and was recorded in every single specimen of $S$. diversicolor, although it did vary in abundance and was most abundant in Papuan marine lakes. Rhodospirillaceae members are bacteria with the ability to grow under distinct environmental conditions, e.g., chemotrophic, phototrophic, organotrophic, autotrophic and anoxic conditions (Esposti et al. 2019). Additionally, some members of Rhodospirillales can thrive in darker habitats due to their ability to use light in the infrared range (Solon et al. 2018). This can be an advantage to $S$. diversicolor due to the reduced penetration of light in marine lakes as a result of dense canopy or the presence of coloured terrestrial organic matter (Karlsson et al. 2009). Although recorded in all samples, the order Rhodospirillales was most abundant in marine lake samples from $\mathrm{Pa}$ pua and open sea samples from Taiwan and less abundant in the marine lakes of Berau, particularly lake Haji Buang.

\section{Conclusion}

In recent years, a number of studies have shown that sponge-associated microbial communities are largely host species specific and tend to be stable across different geographical and environmental settings (Webster and Thomas 2016). In the present study, variation among samples from different geographical locations and the degree of connection of the lakes to the surrounding marine environment also appear to play a role in structuring sponge prokaryotic communities. Although previous studies have shown that the host sponge species is the major factor that structures the sponge symbiont community, our results suggest that geographical location and, for sponges inhabiting marine lakes, connectivity to the surrounding environment, also appear to play a significant role.

\section{Supplementary information}

Supplementary information accompanies this paper at https://doi.org/10 1186/s13213-020-01546-z.

Additional file 1. List of samples used in the present study including the sample code (Sample), biotope code (Bio), Location, Habitat, Connection to the open sea (Connection), Biotope, sampling date (Date), sampling site (Site), Country, Depth, Latitude (Lat), Longitude (Lon), Temperature, Salinity and $\mathrm{pH}$. The number of sequences of the most abundant phyla, classes and orders are given as is the dominance (Dom; relative abundance of the most abundant OTU), Dom3 (relative abundance of the three most abundant OTUs), rarefied richness (Richness), Pielou's J (J) and Shannon's H' diversity index $(H)$.

Additional file 2. $\mathrm{Kml}$ file showing sampling locations of Suberites sponges. Samples were collected in marine lakes from a) Berau, Indonesia: Kakaban lake (BrK), Haji Buang lake (BrM) and Tanah Bamban lake (BrT); b) Papua, Indonesia: Marine lake K (PaK), Marine lake M (PaM); and c) open sea habitat in Taiwan (Taw).

Additional file 3. Rarefaction curves of prokaryotic 165 rRNA sequences for S. diversicolor samples from marine lakes and open habitat. Samples were collected from marine lakes in Berau: Kakaban lake (BrK), Haji Buang lake (BrM), Tanah Bamban lake (BrT); Papua: Marine lake K (PaK), Marine lake M (PaM); and from open sea habitat in Taiwan (Taw).

Additional file 4. Multiple comparisons of mean abundance among habitats for phyla and the major proteobacterial classes and orders in the present study. Suberites diversicolor from marine lakes: Berau: Kakaban lake (BrK), Haji Buang lake (BrM), Tanah Bamban lake (BrT); Papua: Marine lake $\mathrm{K}(\mathrm{PaK})$, Marine lake M (PaM); and open sea habitat in Taiwan (Taw). ${ }^{*}(\mathrm{P}<$ $0.05)$; $^{* *}(\mathrm{P}<0.01)$; ** $(\mathrm{P}<0.001)$

Additional file 5. Simper analysis to identify significantly discriminating OTUs between pairs of habitats. Suberites diversicolor from marine lakes: Berau: Kakaban lake (BrK), Haji Buang lake (BrM), Tanah Bamban lake (BrT); Papua: Marine lake K (PaK), Marine lake $\mathrm{M}(\mathrm{PaM})$; and open sea habitat in Taiwan (Taw). * $(P<0.05)$; ${ }^{* *}(P<0.01) ;{ }^{* * *}(P<0.001)$. 
Additional file 6 . List of most abundant OTUs ( $\geq 400$ sequences) including OTU-numbers; total sequences (Abund); taxonomic assignment of OTU, GenBank Genlnfo sequence identifiers (Gl) of closely related organisms identified using BLAST; sequence identity (Seq) of these organisms with our representative OTU sequences; isolation source of organisms identified using BLAST (Source).

\section{Acknowledgements}

We would like to thank Lisa Becking for collecting the Papua specimens in the field and Ristek and LIPI, Indonesia, for supporting the fieldwork. We are also grateful for the support in the field by Julian Cleary, Floris Cleary and Katherine Liao and in the laboratory by Hélder Gomes.

\section{Authors' contributions}

D.F.R.C. and N.J.d.V. designed the study; N.J.d.V. identified the samples; M.R.S.F. and A.R.M.P. performed the laboratory work under the guidance of N.C.M.G.; D.F.R.C. performed the data analysis; M.R.S.F., D.F.R.C., F.J.R.C.C., N.C.M.G., Y.M.H., A.R.M.P. and N.J.d.V. wrote the manuscript. The author(s) read and approved the final manuscript.

\section{Funding}

This work was supported by National Funds through the Portuguese Science Foundation (FCT) within the LESS CORAL [PTDC/AAC-AMB/115304/2009] and the Ecotech-Sponge [PTDC/BIAMIC/6473/2014 - POCI-01-0145-FEDER016531] projects and the Ministry of Science and Technology (MOST), Taiwan to YMH [MOST 105-2621-B-346-002]. Thanks are also due, for the financial support to CESAM (UID/AMB/50017/2019), to FCT/MCTES through national funds, and the co-funding by the FEDER, within the PT2020 Partnership Agreement and Compete 2020. Marina R. S. Ferreira [Ph.D. scholarship: SFRH/ BD/114809/2016] and Ana R.M. Polónia [postdoctoral scholarship: SFRH/BPD/ 117563/2016] were supported by scholarships funded by FCT, Portugal subsidised by National funds MCTES.

\section{Ethics approval and consent to participate}

This article does not contain any studies with human participants or animals performed by any of the authors.

\section{Consent for publication}

N/A

\section{Competing interests}

The authors declare that they have no conflict of interest.

\section{Author details}

${ }^{1}$ Department of Biology \& CESAM, University of Aveiro, Aveiro, Portugal. ${ }^{2}$ Department of Marine Recreation, National Penghu University of Science and Technology, Magong City, Penghu, Taiwan. ${ }^{3}$ Tropical Island Sustainable Development Research Center, National Penghu University of Science and Technology, Magong City, Penghu, Taiwan. ${ }^{4}$ Naturalis Biodiversity Center, Leiden, The Netherlands. ${ }^{5}$ Institute of Environmental Sciences, CML, Leiden University, Leiden, The Netherlands.

\section{Received: 24 May 2019 Accepted: 29 January 2020}

\section{Published online: 06 March 2020}

\section{References}

Balvočiūtè M, Huson DH (2017) SILVA, RDP, Greengenes, NCBI and OTT-how do these taxonomies compare? BMC Genomics 18:114

Becking LE, Cleary DF, de Voogd NJ (2013a) Sponge species composition, abundance, and cover in marine lakes and coastal mangroves in Berau, Indonesia. Mar Ecol Prog Ser 481:105-120

Becking LE, de Leeuw C, Vogler C (2015) Newly discovered "jellyfish lakes" in Misool, Raja Ampat, Papua, Indonesia. Mar Biodivers 45:597-598

Becking LE, de Leeuw CA, Knegt B, Maas DL, De Voogd NJ, Suyatna I, Peijnenburg KT (2016) Highly divergent mussel lineages in isolated Indonesian marine lakes. PeerJ 4:e2496

Becking LE, Erpenbeck D, Peijnenburg KT, De Voogd NJ (2013b) Phylogeography of the sponge Suberites diversicolor in Indonesia: insights into the evolution of marine lake populations. PloS One 8:e75996
Becking LE, Lim SC (2009) A new Suberites (Hadromerida: Suberitidae) species from the tropical Indo West-Pacific. Zool Meded 83:853-862

Becking LE, Renema W, Santodomingo NK, Hoeksema BW, Tuti Y, de Voogd NJ (2011) Recently discovered landlocked basins in Indonesia reveal high habitat diversity in anchialine systems. Hydrobiologia 677:89-105

Bolaños J, De León LF, Ochoa E et al (2015) Phylogenetic diversity of spongeassociated fungi from the Caribbean and the Pacific of Panama and their in vitro effect on angiotensin and endothelin receptors. Mar Biotechnol 17: 533-564

Borchiellini C, Manuel M, Alivon E, Boury-Esnault N, Vacelet J, Le Parco Y (2001) Sponge paraphyly and the origin of Metazoa. J Evol Biol 14:171-179

Burgsdorf I, Erwin PM, López-Legentil S, Cerrano C, Haber M, Frenk S, Steindler L (2014) Biogeography rather than association with cyanobacteria structures symbiotic microbial communities in the marine sponge Petrosia ficiformis. Front Microbiol 5:529

Burgsdorf I, Slaby BM, Handley KM et al (2015) Lifestyle evolution in cyanobacterial symbionts of sponges. MBio 6:e00391-e00315

Callieri C (2017) Synechococcus plasticity under environmental changes. FEMS Microbiol Lett. https://doi.org/10.1093/femsle/fnx229

Caporaso JG, Kuczynski J, Stombaugh J et al (2010) QIIME allows analysis of highthroughput community sequencing data. Nat Methods 7:335-336

Cerrano C, Azzini F, Bavestrello G, Calcinai B, Pansini M, Sarti M, Thung D (2006) Marine lakes of karst islands in Ha Long Bay (Vietnam). Chem Ecol 22:489-500

Cleary DFR (2019) A comparison of microeukaryote communities inhabiting sponges in a Taiwanese coral reef system. Ann Microbiol 69:861-866 https:// doi.org/10.1007/s13213-019-01476-5

Cleary DFR, Becking LE, Polónia AR, Freitas RM, Gomes NCM (2015) Composition and predicted functional ecology of mussel-associated bacteria in Indonesian marine lakes. Antonie van Leeuwenhoek 107:821-834

Cleary DFR, Becking LE, Polónia AR, Freitas RM, Gomes NCM (2016) Jellyfishassociated bacterial communities and bacterioplankton in Indonesian Marine lakes. FEMS Microbiol Ecol 92:fiw064

Cleary DFR, Becking LE, Voogd NJD, Pires AC, Polónia AR, Egas C, Gomes NCM (2013) Habitat-and host-related variation in sponge bacterial symbiont communities in Indonesian waters. FEMS Microbiol Ecol 85:465-482

Cleary DFR, Gomes NCM (2019) Bacterial, archaeal and microeukaryote plankton communities inside and outside of Indonesian marine lakes. J Sea Res 148: 23-32 https://doi.org/10.1016/j.seares.2019.04.001

Cleary DFR, Polónia ARM, de Voogd NJ (2018a) Bacterial communities inhabiting the sponge Biemna fortis, sediment and water in marine lakes and the open sea. Microb Ecol. https://doi.org/10.1007/s00248-018-1156-6

Cleary DFR, Polónia ARM, de Voogd NJ (2018b) A comparison of Prokaryote community composition in two Cinachyrella morphospecies and water from west Papuan marine lakes. FEMS Microbiol Ecol 94:fix175. https://doi.org/10. 1093/femsec/fix175

Cleary DFR, Polónia ARM, Becking LE, de Voogd NJ, Gomes H, Gomes NCM (2018c) Compositional analysis of bacterial communities in seawater, sediment, and sponges in the Misool coral reef system, Indonesia. Mar Biodivers 48:1889-1901

Cleary DFR, Swierts T, Coelho FJRC, Polónia ARM, Huang YM, Ferreira MRS et al (2019) The sponge microbiome within the greater coral reef microbial metacommunity. Nat commun 10:1644

Coelho FJRC, Cleary DFR, Gomes NCM, Pólonia ARM, Huang YM, Liu LL, de Voogd NJ (2018) Sponge prokaryote communities in Taiwanese coral reef and shallow hydrothermal vent ecosystems. Microb Ecol:1-16

Costa R, Keller-Costa T, Gomes NC, da Rocha UN, van Overbeek L, van Elsas JD (2013) Evidence for selective bacterial community structuring in the freshwater sponge Ephydatia fluviatilis. Microb Ecol 65:232-244

de Voogd NJ, Cleary DF, Polónia AR, Gomes N (2015) Bacterial community composition and predicted functional ecology of sponges, sediment and seawater from the thousand islands reef complex, West Java, Indonesia. FEMS Microbiol Ecol 91

Esposti DM, Mentel M, Martin WF, Sousa FL (2019) Oxygen reductases in alphaproteobacterial genomes: physiological evolution from low to high oxygen environments. Front Microbiol 10:499

Freeman CJ, Thacker RW, Baker DM, Fogel ML (2013) Quality or quantity: is nutrient transfer driven more by symbiont identity and productivity than by symbiont abundance? ISME J 7:1116

Giles EC, Kamke J, Moitinho-Silva L, Taylor MW, Hentschel U, Ravasi T, Schmitt S (2012) Bacterial community profiles in low microbial abundance sponges. FEMS Microbiol Ecol 83:232-241 
Goldford JE, Lu N, Bajić D, Estrela S, Tikhonov M, Sanchez-Gorostiaga A, Segrè D, Mehta P, Sanchez A (2018) Emergent simplicity in microbial community assembly. Science 361:469-474. https://doi.org/10.1126/science.aat1168

Gotoh RO, Chiba SN, Goto TV, Tamate HB, Hanzawa N (2011) Population genetic structure of the striped silverside, Atherinomorus endrachtensis (Atherinidae, Atheriniformes, Teleostei), inhabiting marine lakes and adjacent lagoons in Palau: marine lakes are "Islands" for marine species. Genes Genet Syst 86:325-337

Hamner WM, Hamner PP (1998) Stratified marine lakes of Palau (Western Caroline Islands). Phys Geogr 19:175-220

He L, Liu F, Karuppiah V, Ren Y, Li Z (2014) Comparisons of the fungal and protistan communities among different marine sponge holobionts by pyrosequencing. Microbial Ecol 67:951-961

Hentschel U, Hopke J, Horn M, Friedrich AB, Wagner M, Hacker J, Moore BS (2002) Molecular evidence for a uniform microbial community in sponges from different oceans. App Environ Microb 68:4431-4440

Hoeksema BW (2004) Marine biodiversity of the coastal area of the Berau region, East Kalimantan, Indonesia: progress report East Kalimantan program, pilot phase (October 2003): preliminary results of a field survey performed by an Indonesian-Dutch biodiversity research team. Naturalis, Leiden Holthuis LB

Holthuis LB (1973) Caridean shrimps found in land-locked saltwater pools at four Indo-West Pacific localities (Sinai Peninsula, Funafuti Atoll, Maui and Hawaii Islands): with the description of one new genus and four new species. Brill 128:1-48

Huang YM, de Voogd NJ, Cleary DF, Li TH, Mok HK, Ueng JP (2016) Biodiversity pattern of subtidal sponges (Porifera: Demospongiae) in the Penghu Archipelago (Pescadores), Taiwan. J Mar Biol Assoc U K 96:417-427

Jensen S, Fortunato SA, Hoffmann F, Hoem S, Rapp HT, Øvreås L, Torsvik VL (2017) The relative abundance and transcriptional activity of marine spongeassociated microorganisms emphasizing groups involved in sulfur cycle. Microbial Ecol 73:668-676

Karimi E, Keller-Costa T, Slaby BM, Cox CJ, da Rocha UN, Hentschel U, Costa R (2019) Genomic blueprints of sponge-prokaryote symbiosis are shared by low abundant and cultivatable Alphaproteobacteria. Sci Rep UK 9:1999

Karlsson J, Byström P, Ask J, Ask P, Persson L, Jansson M (2009) Light limitation of nutrient-poor lake ecosystems. Nature 460:506

Klei KAB (2016) Holocene mollusk faunas in three marine lakes in Misool, Raja Ampat, Indonesia. Msc. Thesis, University of Amsterdam, p 80

Klindworth A, Pruesse E, Schweer T, Peplies J, Quast C, Horn M, Glöckner FO (2013) Evaluation of general 16S ribosomal RNA gene PCR primers for classical and next-generation sequencing-based diversity studies. Nucleic Acids Res 41:e1-e1

Lee OO, Wang Y, Yang J, Lafi FF, Al-Suwailem A, Qian PY (2011) Pyrosequencing reveals highly diverse and species-specific microbial communities in sponges from the Red Sea. ISME J 5:650-664

Luter HM, Widder S, Botté ES, Wahab MA, Whalan S, Moitinho-Silva L et al (2015) Biogeographic variation in the microbiome of the ecologically important sponge, Carteriospongia foliascens. PeerJ 3:e1435

McDevitt-Irwin JM, Baum JK, Garren M, Vega Thurber RL (2017) Responses of coral-associated bacterial communities to local and global stressors. Front Mar Sci 4:262

Meyerhof MS, Wilson JM, Dawson MN, Michael Beman J (2016) Microbial community diversity, structure and assembly across oxygen gradients in meromictic marine lakes, Palau. Environ Microbiol 18:4907-4919

Moitinho-Silva L, Steinert G, Nielsen S, Hardoim CC, Wu YC, McCormack GP et al (2017) Predicting the HMA-LMA status in marine sponges by machine learning. Front Microbiol 8:752

Morrow KM, Fiore CL, Lesser MP (2016) Environmental drivers of microbial community shifts in the giant barrel sponge, Xestospongia muta, over a shallow to mesophotic depth gradient. Environ Microbiol 18:2025-2038

Müller WE (1998) Origin of Metazoa: sponges as living fossils. Naturwissenschaften $85: 11-25$

Oláh J, Szénási T, Szabó A, Kovács K, Lőw P, Štifanić M, Orosz F (2017) Tubulin binding and polymerization promoting properties of tubulin polymerization promoting proteins are evolutionarily conserved. Biochemistry 56:1017-1024

Park SR, Yoon YJ, Pham JV et al (2019) A review of the microbial production of bioactive natural products and biologics. Front Microbiol 10:1404

Polónia ARM, Cleary DF, Freitas R, de Voogd NJ, Gomes N (2015) The putative functional ecology and distribution of archaeal communities in sponges, sediment and seawater in a coral reef environment. Mol Ecol 24:409-423

Polónia ARM, Cleary DFR (2019) Archaeal communities in sponge, sediment and water from marine lakes and open water habitats. Mar Biol Res 15:259-274
Polónia ARM, Cleary DFR, Freitas R, Coelho FJRC, de Voogd NJ, Gomes NCM (2016) Comparison of archaeal and bacterial communities in two sponge species and seawater from an Indonesian coral reef environment. Mar Genom 29:69-80

Quast C, Pruesse E, Yilmaz P et al (2012) The SILVA ribosomal RNA gene database project: improved data processing and web-based tools. Nucl Acids Res 41: D590-D596

R Core Team (2013) R: A language and environment for statistical computing. R Foundation for Statistical Computing, Vienna ISBN 3-900051-07-0. Available from http://www.Rproject.orghttp://www.R-project.org

Reynolds CS (1980) Phytoplankton assemblages and their periodicity in stratifying lake systems. Ecography 3:141-159

Ruetzler K (2004) Sponges on coral reefs: a community shaped by competitive cooperation. Boll Mus Ist Biol Univ Genova 68:85-148

Saitoh SI, Suzuki H, Hanzawa N, Tamate HB (2011) Species diversity and community structure of pelagic copepods in the marine lakes of Palau. Hydrobiologia 666:85-97

Schmitt S, Tsai P, Bell J, Fromont J, llan M, Lindquist N et al (2012) Assessing the complex sponge microbiota: core, variable and species-specific bacterial communities in marine sponges. ISME J 6:564-576

Solon AJ, Vimercati L, Darcy JL, Arán P, Porazinska D, Dorador C et al (2018) Microbial communities of high-elevation fumaroles, penitentes, and dry tephra "soils" of the Puna de Atacama volcanic zone. Microb Ecol 76:340-351

Steinberg CE, Hartmann HM (1988) Planktonic bloom-forming Cyanobacteria and the eutrophication of lakes and rivers. Freshwater Biol 20:279-287

Strelkov P, Shunatova N, Fokin M, Usov N, Fedyuk M, Malavenda S et al (2014) Marine Lake Mogilnoe (Kildin Island, the Barents Sea): one hundred years of solitude. Polar biol 37:297-310

Swierts T, Cleary DFR, de Voogd NJ (2018) Biogeography of prokaryote communities in closely related giant barrel sponges across the Indo-Pacific FEMS Microbiol Ecol 94:fiy194 https://doi.org/10.1093/femsec/fiy194

Taylor M, Radax R, Steger D, Wagner M (2007) Sponge-associated microorganisms: evolution, ecology, and biotechnological potential. Microbiol Mol Biol R 71:295-347

Taylor MW, Schupp PJ, De Nys R, Kjelleberg S, Steinberg PD (2005) Biogeography of bacteria associated with the marine sponge Cymbastela concentrica. Environ Microbiol 7:419-433

Thiele S, Richter M, Balestra C, Glöckner FO, Casotti R (2017) Taxonomic and functional diversity of a coastal planktonic bacterial community in a riverinfluenced marine area. Mar Genom 32:61-69

Tomascik T, Mah AJ (1994) The ecology of 'Halimeda lagoon': an anchialine lagoon of a raised atoll, Kakaban Island, East Kalimantan, Indonesia. Trop Biodiv 2:385-399

Tomascik T, Mah AJ, Nontji A, Moosa MK (1997) The ecology of the Indonesia seas. Part II, Periplus

Turque AS, Batista D, Silveira CB, Cardoso AM, Vieira RP, Moraes FC et al (2010) Environmental shaping of sponge associated archaeal communities. PLoS One 5:e15774

Urakawa H, Martens-Habbena W, Stahl DA (2010) High abundance of ammoniaoxidizing Archaea in coastal waters, determined using a modified DNA extraction method. Appl Environ Microbiol 76:2129-2135. https://doi.org/10. 1128/AEM.02692-09

Wang Q, Garrity GM, Tiedje JM, Cole JR (2007) Naive Bayesian classifier for rapid assignment of rRNA sequences into the new bacterial taxonomy. Appl Environ Microbiol 73:5261-5267

Webster NS, Luter HM, Soo RM, Botté ES, Simister RL, Abdo D, Whalan S (2013) Same, same but different: symbiotic bacterial associations in GBR sponges. Front Microbiol 3:444

Webster NS, Taylor MW, Behnam F, Lücker S, Rattei T, Whalan S et al (2010) Deep sequencing reveals exceptional diversity and modes of transmission for bacterial sponge symbionts. Environ Microbiol 12:2070-2082

Webster NS, Thomas T (2016) The sponge hologenome. MBio 7:e00135-e00116

Xie W, Zhang C, Zhou X, Wang P (2014) Salinity-dominated change in community structure and ecological function of Archaea from the lower Pearl River to coastal South China Sea. Applied Microbiology and Biotechnology 98:79717982. https://doi.org/7910.1007/s00253-00014-05838-00259

\section{Publisher's Note}

Springer Nature remains neutral with regard to jurisdictional claims in published maps and institutional affiliations. 